\title{
Cognitive processing in literate and illiterate subjects: A review of some recent behavioral and functional neuroimaging data
}

\author{
KARL MAGNUS PETERSSON ${ }^{1}$, ALEXANDRA REIS ${ }^{1,2}$ and MARTIN INGVAR ${ }^{1}$ \\ ${ }^{1}$ Department of Clinical Neuroscience, Karolinska Institutet, Stockholm, Sweden \\ ${ }^{2}$ Area Departamental de Ciencias da Educacão e Psicologia, Universidade do Algarve, Faro, Portugal
}

Petersson, K. M., Reis, A. \& Ingvar, M. (2001). Cognitive processing in literate and illiterate subjects: A review of some recent behavioral and functional neuroimaging data. Scandinavian Journal of Psychology, 42, 251-267.

\begin{abstract}
The study of illiterate subjects, which for specific socio-cultural reasons did not have the opportunity to acquire basic reading and writing skills, represents one approach to study the interaction between neurobiological and cultural factors in cognitive development and the functional organization of the human brain. In addition the naturally occurring illiteracy may serve as a model for studying the influence of alphabetic orthography on auditory-verbal language. In this paper we have reviewed some recent behavioral and functional neuroimaging data indicating that learning an alphabetic written language modulates the auditory-verbal language system in a non-trivial way and provided support for the hypothesis that the functional architecture of the brain is modulated by literacy. We have also indicated that the effects of literacy and formal schooling is not limited to language related skills but appears to affect also other cognitive domains. In particular, we indicate that formal schooling influences 2D but not 3D visual naming skills. We have also pointed to the importance of using ecologically relevant tasks when comparing literate and illiterate subjects. We also demonstrate the applicability of a network approach in elucidating differences in the functional organization of the brain between groups. The strength of such an approach is the ability to study patterns of interactions between functionally specialized brain regions and the possibility to compare such patterns of brain interactions between groups or functional states. This complements the more commonly used activation approach to functional neuroimaging data, which characterize functionally specialized regions, and provides important data characterizing the functional interactions between these regions.
\end{abstract}

Key words: Illiteracy, phonological processing, memory, visual naming, structural equation modeling, PET

Karl Magnus Petersson, Cognitive Neurophysiology R2-01, Karolinska Hospital, 17176 Stockholm, Sweden. E-mail: karl.magnus.petersson@ks.se

\section{INTRODUCTION}

The acquisition of alphabetic orthographic knowledge, that is, learning an alphabetic written language appears to influence the auditory-verbal language system in a nontrivial way and provide support for the hypothesis that the functional architecture of the brain is modulated by literacy (Petersson et al., 2000). Both behavioral and functional neuroimaging data are consistent with this hypothesis (Castro-Caldas et al., 1998; Petersson et al., 2000; Reis \& Castro-Caldas, 1997). In addition, functional neuroimaging data indicate that there are inter-hemispheric regional cerebral blood flow differences in the posterior parietal cortex between the two literacy groups during immediate verbal repetition tasks (Petersson et al., 1998). These interhemispheric differences are paralleled by morphological findings, indicating that the part of corpus callosum relaying the inter-hemispheric connections between the left and right posterior parietal cortices is larger in literate compared to illiterate subjects, possibly reflecting an effect of formal schooling (Castro-Caldas et al., 1999). In short, these data indicate that the learning and acquisition of written language skills significantly modulates the spoken language system. However, it is still unclear which processes and mechanisms mediate the influence of literacy. It is also unclear which parts of the cognitive system and which processing levels formal education and orthographic knowl- edge affect. Additional data indicate that also other cognitive functions are influenced by formal education. Behavioral studies have demonstrated that the level of literacy (including illiteracy) influences the performance of several commonly used tasks in neuropsychological assessment (e.g., Ardila et al., 1989; Lecours et al., 1987a; Lecours et al., 1987b; Manly et al., 1999; Ostrosky et al., 1991; Rosselli et al., 1990). For example, the level of literacy influences the performance when subjects name 2D pictorial representations of objects (Kremin et al., 1991; Manly et al., 1999; Reis et al., 1994; Rosselli et al., 1990).

The objective of this paper is to describe some behavioral and functional neuroimaging results from a series of experiments with an illiterate population and their matched literate controls. The rational behind this work is to investigate different aspects of the influence of formal education and literacy on the cognitive system of the human brain. In this context, it is important to ensure that the subjects studied are not cognitively impaired and also that the illiterate subjects are equal to the literate subjects, in as many relevant respects as is possible, except for the direct consequences of not having had the opportunity to receive formal education. For example, one needs to exclude learning disabilities and other potentially confounding factors. In our studies we have attempted to match the different literacy groups as far as possible in terms of several relevant variables (e.g., age, sex, general health, socio-cultural background, and 
level of everyday functionality). The illiterate subjects participating in our studies did not receive formal education for specific social reasons (cf. below) and not because of overt low intelligence, learning disability, or some similar factor (cf. Reis et al., Submitted-a).

\section{THE NATURALLY OCCURRING ILLITERACY OF SOUTHERN PORTUGAL}

Illiteracy for social reasons is still a common finding in many parts of the world. In Portugal some forty or fifty years ago, it was not uncommon that at least one of the daughters of a family did not enter school at the age of six, the common age for school start. One of the older daughters, not seldom the oldest, was usually engaged at home in the daily workings of the household and commonly started to work outside the family at a relatively early age in order to contribute the family economy. In larger families, one of the older daughter typically helped to take care of the younger siblings. In contrast, the younger children were generally sent to school when they reached the age of 6 or 7. Also, since the younger siblings spent a significant part of the day at school they did not have to be taken care of at home.

In our illiterate sample the main reasons for not entering school at the appropriate age were the following: care taking of the younger siblings, the school location was too far from home, cultural reasons (i.e., it was not viewed as necessary for a girl to acquire an education outside home), and economical factors. The greater likelihood that an older (oldest) daughter stayed illiterate while the younger sibling became literate may at least in principle introduce a birth order effect. It has been suggested that birth order may affect cognitive functions, in particular related to being firstborn compared to being of later birth rank. In this context it should be noted that the illiterate subjects were sampled from the older daughters and even if the oldest daughter may have been selected more often, being the oldest daughter is of course not the same as being the firstborn. More importantly, the screening procedures used in the subject selection (cf. below) attempts to exclude subjects with cognitive dysfunction or learning disability. Furthermore, all subjects included in our studies function at a similar level in ordinary everyday life. In addition, the formal schooling factor appears to affect specific tests while other tests are unaffected (cf. below). Together this indicates no general deficit among our illiterate sample compared to the literate sample.

The fishermen community of southern Portugal, where our studies have been conducted, is socio-culturally relatively homogeneous and the majority of the population has lived most of their lives in the community with local surroundings. Mobility within this region was relatively uncommon because the main sources of income were related to the fishing and farming. Literate and illiterate subjects live intermixed in the same community and participate actively on similar terms. Illiteracy is not perceived as a functional handicap. In this community, literacy and in particular higher education, was considered relatively less important while other useful skills were emphasized. Overall, a similar socio-cultural background influences both literate and illiterate subjects on similar grounds. It should also be noted that the literate subjects participating in our studies are not highly educated. In short, the main difference between the two literacy groups relates to reading and writing and other skills acquired during the first years of school attendance.

\section{Subject selection}

In a recent socio-demographic characterization of our study population we describe the selection procedures and selection criteria in greater detail (Reis et al., Submitted-a). Here we describe these procedures more briefly. The subjects included all volunteered and were screened with two semistructured interviews. The socio-cultural interview assess socio-cultural variables (e.g., occupation, literacy level acquired in case of being a literate or, in case of an illiterate subject, the reasons why they were illiterates and the parent's literacy level, etc.) and the medical interview assess health and medical variables. In addition, the subjects were cognitively screened with a short neuropsychological test battery for mental state assessment (including oral/written language, verbal memory, basic information, orientation, mental calculation, and verbal abstraction; cf. Garcia, 1984; Garcia \& Guerreiro, 1983). The testing occurred in a quiet environment in which the participant and the tester are sitting at a table. Briefly, a questionnaire is used to assess the socio-cultural, familiar and professional background of the subjects. The questions are focus on their literacy background, the reasons why they had or had not received formal schooling, the literacy level and profession of the parents and relatives, the subjects' past and present occupation, and their daily life and occupational performance. A subject is classified as illiterate if the subject has not been exposed to formal schooling (for socio-cultural reasons) and has no experience of reading or writing. These subjects are also screened to verify that they were unable to apply grapheme-phoneme associations. For example, they are asked to read common words (e.g., hospital) and letter sequences (upper/lower case). The ones that are unable to read and write are included in the illiterate group. Illiterate subjects can often sign their names, for example, to occasionally sign work, administrative or governmental papers, and this ability is not an exclusion criterion. The literate subjects have regular reading/writing habits and had received at least 4 years of formal education. The screening of the literate subjects also included a short reading/writing test, including word, sentence and text reading (aloud), reading comprehension, and word writing. 
The demographic characteristics of the overall sample

So far we have screened and tested 85 female volunteers recruited with the help of the local doctor, contacts of already recruited subjects, and by word-of-mouth (subsample 1) and several day-centers (sub-sample 2) where older people socialize, participate in social activities. Altogether 66, 48 from sub-sample 1 and 18 subjects from sub-sample 2 were included for further investigations (Table 1). From the overall sample 19 subjects were excluded (Table 2). The sample was divided into three literacy groups: completely illiterate subjects $(\mathrm{G} 1)$, literates with 4 years of schooling $(\mathrm{G} 2)$, and literates with more than 4 years of schooling (G3). It should be noted that the exclusion of subjects did not affect the results presented below.

Characterisation of the professional status of the overall sample

To characterize the professional background of the subjects (Table 3) we used a sub-scale of the European Brain Injury Scale (Brooks \& Truelle, 1994). The distribution of professional status in Table 3 indicates that the differences between groups were limited (none of the differences were significant, as evaluated by the Wilcoxon matched paired test). This was also the case for sub-sample 1 . In particular, the average score was similar for the three literacy groups (no significant difference).

Only subjects from sub-sample 1 have been used in our behavioral, functional neuroimaging and neuroanatomic studies (with the exception of Reis et al. (1994)). For a more detailed analysis and discussion of the socio-demographic characteristics see Reis et al. (Submitted-a).

\section{Verbal fluency and digit span}

In the following section we will focus on some results from behavioral experiments (Reis et al., Submitted-a) related or relevant to auditory-spoken or written language (e.g., verbal working memory, short-term memory, and visual processing). However, we start with an example indicating the importance of using ecologically relevant tasks when studying different literacy groups.

We analyzed a data set from the 48 subjects -23 illiterates (mean age of $66.2 \pm 4.9$ ), 18 literate subjects with four years of formal schooling (mean age of $61.9 \pm 7$ ) and 7 literate subjects with more than four years of education (mean age $63.6 \pm 4.2$ and mean years of education $9.6 \pm 4.2$ ). The three groups did not differ significantly on age (Median Test $\chi^{2}=2.01, P=0.4 ;$ Kruskal-Wallis, $H=5.5, P=0.06$ ).

Subjects performed a verbal verbal fluency task and were instructed to produce as many words as possible during one

Table 1. The distribution of years of education and local of recruitment of the overall sample

\begin{tabular}{|c|c|c|c|c|c|}
\hline \multirow[b]{2}{*}{ Literacy Level } & \multicolumn{2}{|c|}{ Sub-sample 1} & \multicolumn{2}{|c|}{ Sub-sample 2} & \multirow[b]{2}{*}{$\mathrm{N}$} \\
\hline & Age & $\begin{array}{l}\text { Years of } \\
\text { education }\end{array}$ & Age & $\begin{array}{l}\text { Years of } \\
\text { education }\end{array}$ & \\
\hline $\begin{array}{l}\text { Illiterates } \\
(\mathrm{G} 1)\end{array}$ & $\begin{array}{l}66.2 \pm 4.9 \\
{[57-76]} \\
n=23\end{array}$ & - & $73.1 \pm 3.6$ & $\begin{array}{l}- \\
{[70-79]} \\
n=8\end{array}$ & 31 \\
\hline $\begin{array}{l}4 \text { years of schooling } \\
\text { (G2) }\end{array}$ & $\begin{array}{l}61.9 \pm 7 \\
{[51-76]} \\
n=18\end{array}$ & $\begin{array}{l}4 \pm 0 \\
{[4-4]}\end{array}$ & $\begin{array}{l}73 \pm 6.1 \\
{[65-83]} \\
n=8\end{array}$ & $\begin{array}{l}4 \pm 0 \\
{[4-4]}\end{array}$ & 26 \\
\hline $\begin{array}{l}\text { More than } 4 \text { years of } \\
\text { schooling } \\
\text { (G3) }\end{array}$ & $\begin{array}{l}63.6 \pm 4.2 \\
{[56-69]} \\
n=7\end{array}$ & $\begin{array}{l}9.6 \pm 4.2 \\
{[6-12]}\end{array}$ & $\begin{array}{l}78 \pm 1.4 \\
{[77-79]} \\
n=2 \\
18\end{array}$ & $\begin{array}{l}7 \pm 2.8 \\
{[5-9]}\end{array}$ & 9 \\
\hline
\end{tabular}

Table 2. The subjects excluded $(\mathrm{n}=19)$ from the initial overall sample $(\mathrm{n}=85)$. The subjects were excluded for the reasons listed in the table

\begin{tabular}{lll}
\hline & Illiterates & $\begin{array}{c}4 \text { years of } \\
\text { schooling }\end{array}$ \\
\hline Battery of Mental tests impaired (12) & 9 & 3 \\
Psychiatric history (3) & 2 & 1 \\
Neurological history (2) & 1 & 1 \\
History of learning disability (1) & 1 & - \\
Drop out (1) & 1 & - \\
\hline
\end{tabular}


Table 3. Professional status of the overall sample

\begin{tabular}{|c|c|c|c|}
\hline & $\begin{array}{l}\text { Illiterates } \\
n=31\end{array}$ & $\begin{array}{l}4 \text { years } \\
n=26\end{array}$ & $\begin{array}{l}>4 \text { years } \\
n=9\end{array}$ \\
\hline 0 Professional, executive, manager & - & - & - \\
\hline 1 Intermediate, head clerk, businessman, large scale farmer & - & - & $22 \%(2 / 0)$ \\
\hline 2 Skilled occupations, small farmer, office worker, foreman, shop keeper & - & $16 \%(2 / 2)$ & $22 \%(1 / 1)$ \\
\hline 3 Semi-skilled occupations, lower office workers & $68 \%(19 / 3)$ & $48 \%(11 / 2)$ & $11 \%(1 / 0)$ \\
\hline 4 Unskilled occupations & $13 \%(2 / 2)$ & $4 \%(1 / 0)$ & - \\
\hline 5 Other (housewife) & $19 \%(3 / 3)$ & $32 \%(4 / 4)$ & $44 \%(3 / 1)$ \\
\hline
\end{tabular}

Table 4. Performance of the literacy groups on two neuropsychological tests (sub-sample 1). Mean, standard deviation, minimum and maximum for each literacy group: illiterates (G1), literates with 4 years of education (G2), and more than 4 years of education (G3). The P-values relates to the overall Kruskal-Wallis group comparison and are presented after the descriptive statistics of each group. The right most column represents the significant between group effects (Mann-Whitney U Test)

\begin{tabular}{lllll}
\hline $\begin{array}{l}\text { Neuropsychological } \\
\text { Tests }\end{array}$ & $\begin{array}{l}\text { Illiterates } \\
\text { G1, } n=23\end{array}$ & $\begin{array}{l}\text { 4 years } \\
\text { G2, } n=18\end{array}$ & $\begin{array}{l}\text { G years } \\
\text { G3, } n=7\end{array}$ & P \\
\hline Verbal Fluency & $15.5 \pm 2.7$ & $15.5 \pm 3.3$ & $14.3 \pm 2.2$ & n.s. \\
Digit Span & {$[12-21]$} & {$[9-20]$} & {$[10-17]$} & $7 \pm 1.8$ \\
& $4.1 \pm 0.9$ & $5.2 \pm 1.4$ & {$[4-9]$} & G1vsG2vsG3 \\
\hline
\end{tabular}

minute from a given semantic category. We asked the subjects to name different things one can buy at the supermarket. This is perhaps a less common semantic category used in verbal fluency tasks but appears to be more ecologically relevant in our study population. The 3 literacy groups compared here did not show any significant difference on this particular verbal fluency task (Table 4). There are however reports of fluency differences between literacy groups, both with semantic and phonological criteria (Ostrosky-Solís et al., 1999; Ostrosky-Solís et al., 1998; Reis \& Castro-Caldas, 1997). The absence of literacy effect on our verbal fluency task is likely related to the particular choice of semantic category. Producing names of things that one can buy at the supermarket is a task that is less artificial and more adapted to the reality and every day life of the subjects compared to other common criteria. For example, production of names of animals or furniture may be influenced by frequency effects or perhaps organizational and retrieval strategies that can be modulated by formal schooling. In contrast, shopping at the supermarket is something that both the literate and illiterate subjects of our study population do at a regular and comparable level. This is also consistent with the fact that results, comparing literacy groups, on verbal fluency tasks have yielded contradictory results when different semantic criteria has been used. In contrast, clear differences have been shown with a phonological criterion indicating that the literate perform better than the illiterate subjects (Manly et al., 1999; Ostrosky-Solís et al., 1999; Ostrosky-Solís et al., 1998; Reis \& Castro-Caldas, 1997).
In accordance with previous data (Ardila et al., 1989; Garcia \& Guerreiro, 1983; Reis et al., 1995), there was a significant literacy effect on the digit span task. In other words, the literates performed significantly better than the illiterate subjects (Table 4). It was also noted that the performance on the digit span task was sensitive to the level education (i.e., the G2 vs. G3 effect was significant). This indicates that not only literacy as such but also the years of formal education can be an important factor in influencing cognitive processing. The literacy effect on digit span has also been investigated in terms of an influence of the magnitude component of digit representations (Reis et al., 1995). To test the magnitude hypothesis Reis and col. (Reis et al., 1995), compared the performance of literate and illiterate subjects on a digit span task either with digits smaller or larger then five. The illiterate subjects performed significantly worse on digits $>5$ as compared to digits $<5$, while this was not the case for the literate group.

\section{FORMAL SCHOOLING INFLUENCES 2D BUT NOT 3D NAMING SKILLS}

As indicated above, the level of formal schooling or literacy appears to influence the performance when naming 2D pictorial representations of objects (Reis et al., 1994; Reis et al., Submitted-b). Naming objects or their pictorial 2D representations are common tasks used in neuropsychological assessment and research. The performance on simple visual naming tasks is mainly dependent on the systems for 
visual recognition (including visual attention) and language processing as well as the interaction between these systems.

In our study population learning and practice in interpreting schematic $2 \mathrm{D}$ representations most often took place during school attendance simultaneously with the acquisition of written Portuguese. Reading and writing are dependent on advanced skills in producing, coding, and decoding $2 \mathrm{D}$ representations. It is likely that the production and interpretation of $2 \mathrm{D}$ representations of real objects is significantly more practiced in the literate compared to the illiterate group. In other words, literate subjects are in general more practiced in coding and decoding 2D material in terms of figurative/symbolic representations, while illiterate subjects have generally received relatively little systematic practice in interpreting conventional visuosymbolic representation. Here we briefly describe the results from a visual naming experiment (Reis et al., 1999a; Reis et al., 1999b). For further details and a full discussion see (Reis et al., Submitted-b).

\section{Stimuli and task procedures}

Sixty-five object drawings easily match to a common everyday real object were selected from the set of Snodgrass and Vanderwart (Snodgrass \& Vanderwart, 1980). Common everyday objects were selected to minimize possible vocabulary differences between subjects. Each drawing was closely matched with a similar real object. A digital camera was used to make a photo of each object. The 65 items were divided into 3 sets $(22 / 22 / 21)$. The semantic categories were randomly distributed between the 3 sets. For each set of items, 3 corresponding lists of real objects $(\mathrm{O})$, photos $(\mathrm{P})$ and line drawings (D) were generated. The D- and $\mathrm{P}$ stimuli were displayed on a computer screen and the computer was also used to register reaction times (RTs). The whole experiment was run in a dark room. The same paced presentation paradigm was used for each presentation mode (PM: D, P, O). Each drawing and photograph was displayed for $5 \mathrm{~s}$ and voice detection equipment registered the RT between the onset of the display and the onset of the response. A similar procedure was used to register the $\mathrm{O}$ data. The real objects were displayed in a $50 \times 50 \times 50 \mathrm{~cm}$ black box, which was lit with a lamp for the same display time as in D and P. The RTs were registered in the same way as for $\mathrm{D}$ and $\mathrm{P}$ stimuli.

In this study 20 illiterate (mean age $65.9 \pm 3.9 ; 57-72$ yrs) and 20 literate females $(63.5 \pm 4.9 ; 56-73$ yrs $)$ and a mean literacy level of $5.7 \pm 2.7 \mathrm{yrs}$ of education from sub-sample 1 participated. The mean age difference was not significant $(P=0.11)$. Each subject was tested in two blocks; in each block, 3 different sets of items were randomly chosen without replacement to be presented in one of the PM. The presentation order was identical for each group in both blocks but randomized among subjects. After the experiment, a post-experiment interview was conducted with each subject, to investigate the reasons for incorrect responses or response failure. During the interview, the items that had elicited erroneous responses were presented again (same PM and order in which the failures occurred), and the subject was asked to name the items with no time constrains. If the subject still did not identify the item correctly, a semantic cue was provided, in a responsive naming task, in order to differentiate the reasons for the errors made. The responses obtained in this way were not included in the performance analysis but only used in the qualitative error analysis.

\section{Accuracy analysis and reaction time analysis}

Before the statistical analysis was undertaken we calculated the percentage of correct responses for each item in each presentation mode. To minimize the potential effects of the quality or visual information of the presented items (e.g., needle) or the frequency of encounter in daily life (e.g., screw-nut), the responses on items for which more than $50 \%$ of the subjects in both groups made incorrect responses in one presentation mode were excluded from further analysis. The responses for each block were pooled across each PM.

We calculated the total scores of correct answers for each subject, block, and PM, and the data were first analyzed with a nested repeated measures mixed effects ANOVA (considering all the factors of the experimental design, i.e., block, PM, literacy group, and subject; this last factor was nested within the literacy factor and considered a random effect). The results (Table 5, Fig. 1) show a significant block effect $[F(1,38)=24.5 ; P<0.001]$, PM effect $[F(2,76)=20.6$; $P<0.001]$, literacy effect $[F(1,38)=20.9 ; P<0.001]$, and a significant interaction between $\mathrm{PM}$ and literacy $[F(2,76)=14 ; P<0.001]$.

The significant interaction related to the fact that the PM effect was significant in the illiterate group and not significant in the literate group (non-parametric statistics yielded fully consistent results with the ANOVA; cf. Table 5). Within-group comparisons confirmed this (Wilcoxon matched pairs test; the illiterate group, block 1: D vs. $\mathrm{P}, P=01$; D vs. $\mathrm{O}, P<0.001$; P vs. $\mathrm{O}, P=0.02$; block 2 : D vs. $\mathrm{O}, P=0.03)$. In contrast, as noted above, there was no significant difference in the literate group.

The mean reaction times (RTs) were calculated for each subject, block, and PM. In order not to confound literacy effect with performance differences, we excluded misregistered responses (e.g., hardware/software failure or ambient noise) and RTs from incorrect or no-answers. Only RTs from correct responses were included in the analysis. In order to test for block and literacy effects, independent of item specific effects, the items were matched across blocks and between groups for each PM. The results showed a significant block effect $[F(1,34)=8.1 ; \quad P=0.008]$ and literacy effect $[F(1,34)=15.4 ; P<0.001]$. The two literacy groups differed significantly with respect to RTs, both for drawings [block $1, F(1,34)=4.4, P=0.045$; block 2, 
Table 5. Accuracy rates of the study groups in an object naming task with drawings, photos and objects. The results from the within-group (Friedman ANOVA) and between-group comparisons (Mann-Whitney $U$ test). Means and standard deviations of the correct number of responses with $p$-values from corresponding tests. $P M=$ presentation mode, $D=$ drawings, $P=$ Photos, and $O=$ objects

\begin{tabular}{llll}
\hline PM & $\mathrm{D}$ & $\mathrm{P}$ & $\mathrm{O}$ \\
\hline 1st Block & & & \\
Illiterate & $14.9(2.2)$ & $16.5(1.5)$ & $17.4(1)$ \\
Literate & $17.2(1.4)$ & $17.2(1.3)$ & $17.7(1.2)$ \\
& $U=74.5 ; p=0.0007$ & $U=150 ; p=0.18$ & $U=175 ; p=0.51$ \\
2nd Block & $16.3(1.6)$ & $17(1.4)$ & $17.5(1.3)$ \\
Illiterate & $18(1.2)$ & $17.5(1.5)$ & $18(1.1)$ \\
Literate & $U=86.5 ; p=0.002$ & $U=166.5 ; p=0.37$ & $U=163 ; p=0.32$ \\
& & & $p=0.63$ \\
\hline
\end{tabular}
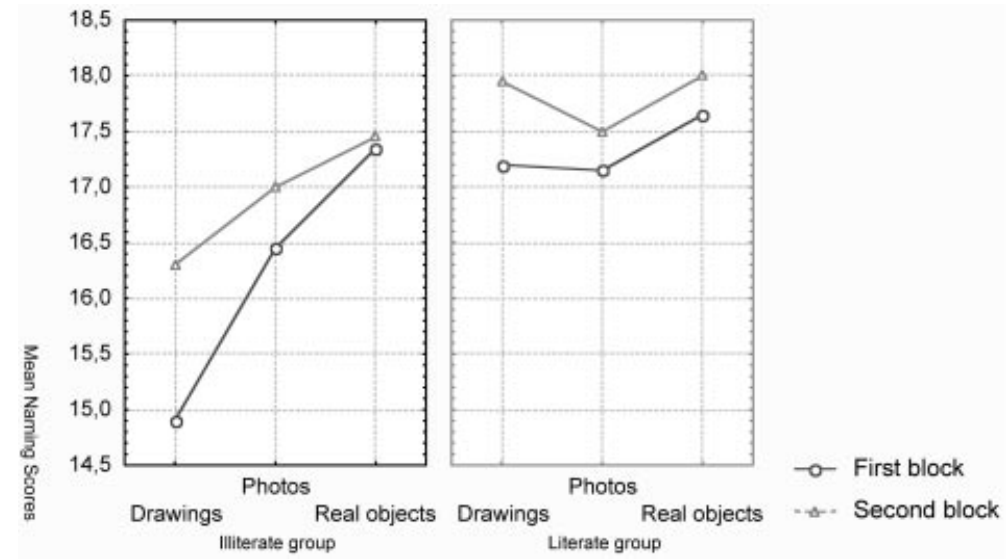

Fig. 1. Accuracy data: Mean visual naming scores for the literate and illiterate group according to block and presentation modes.

$F(1,34)=3.6, P=0.066$ ] and for photos [block 1, $F(1,34)$ $4.3, P=0.045$; block $2, F(1,34)=4.3, P=0.047]$, but there was no significant difference for real objects in either block.

\section{Qualitative error analysis}

Two independent observers classified the incorrect responses. One of the observers was blind to the levels of all experimental factors. Both observers classified the incorrect responses identically. We classified the errors as follows: visually related errors (visual recognition error (VRE), no visual recognition (NVR)), language related errors (semantically related lexical naming error (SR), and no lexical access or omissions (NLA)). This is similar to the approach of Newcombe et al. (1971). So, we investigated whether the error patterns in the two literacy groups were different in terms of distribution of language related (SR + NLA) and visually related (VRE + NVR) errors in each presentation mode. There were significant group differences (block 1) when naming drawings and photos $\left(\chi^{2}=3.99, P=0.04\right.$; $\left.\chi^{2}=8.59, \quad P=0.003\right)$, while there was no significant difference during real object naming $\left(\chi^{2}=0.65, P=0.61\right.$; the group differences were similar in block 2).
In summary, these results show that the illiterates have lower naming scores compared to the literate subjects when naming visually presented drawings of common everyday objects (and to a lesser extent photos). In contrast, there was no significant difference between the two literacy groups when naming the corresponding common everyday real objects. The analysis of the reaction times of the correct responses also demonstrated a significant literacy effect. In particular, the illiterate subjects responded with a longer mean reaction time when they correctly named drawings and photos compared to the literate group, while this was not the case when naming the real objects. The absence of group differences when successfully naming real objects indicate that the reaction time differences on drawings and photos is not simply related to slower language processing in general. Instead, the longer processing time may be related to the processing of visual information. This would indicate that $2 \mathrm{D}$ visual processing is in some sense different in illiterate compared to literate subjects. Alternatively, the longer response latencies may be related to the interaction between the visual (in a broad sense, i.e., including visual attention) and the language system. In other words, the interface between the two systems may not be configured in the same 
way, leading to differences in the effectiveness of the necessary information transfer. The result of the error analysis is consistent with this interpretation, since the illiterate subjects made relatively more visually related errors than language related while the pattern was the opposite for the literate group. In fact the qualitative distribution of errors was not significantly different for real object naming between groups. Taken together this interpretation is consistent with a recent suggestion that orthographic knowledge is an integral component of the general visual processing system (Patterson \& Lambon Ralph, 1999) indicating that the acquisition of alphabetic orthographic knowledge may affect specific components of the general system for visual processing. Interestingly, a positive correlation between reading abilities and the capacity to name line drawings have also been reported (Goldblum \& Matute de Duran, 2000). Interpreted in this context, the correlation may be related to the fact that decoding and interpretation of $2 \mathrm{D}$ representations is most often a significantly more trained skill in literate than in illiterate subjects.

\section{WORD AND PSEUDO-WORD REPETITION IN LITERATE AND ILLITERATE SUBJECTS}

Pseudo-word repetition and digit span tasks are good measures of working memory capacities and these measures are also related to reading achievements in children (Gathercole, 1995a; Gathercole, 1995b; Gathercole, 1995c; Gathercole \& Baddeley, 1995). The concept of a verbal short-term working memory system subserving the representation and on-line processing of series of digits and words was proposed by Baddeley and Hitch (Baddeley, 1992; Baddeley \& Hitch, 1974). Additional research points toward a role of verbal working memory and the efficiency of phonological processing in relation to reading skills (Brady, 1991). It has also been suggested that the one of the primary roles of the phonological loop, a subsystem of working memory, is to store sound patterns while more permanent memory records are being constructed. This suggests that the phonological loop may serve as a language learning device, being an integral part of the systems for spoken and written language acqusition (Baddeley et al., 1998).

Reis et al. (1997) concluded that illiterate performed similarly to literate subjects on word repetition, while there was a significant difference on pseudo-word repetition. The behavioral results from a recent the PET study were broadly consistent with these findings (Castro-Caldas et al., 1998). Specifically, the literate performed at $98 \%$ while the illiterate subjects performed at $92 \%$ correct on word repetition. Although small, this difference reached statistical significance. In contrast, on pseudo-word repetition the literate performed at $84 \%$ and the illiterate group at $33 \%$ correct. We have previously suggested that the inability to handle certain aspects of sub-lexical phonological structure indicates that the phonological representations or the processing of phonological information by the verbal short-term working memory are differently developed in literate subjects compared to illiterate subjects. Taken together this indicates that there may exist a relation between the acquisition of alphabetic orthographic knowledge and some aspects of phonological processing.

A detailed account of the selection and experimental procedures of the PET study of verbal repetition can be found in Castro-Caldas et al. (1998). In brief, twelve righthanded women (6 literate, 6 illiterate) were included in the study. The literate women had received 4 years of schooling and performed normally on reading comprehension and writing tests. Six lists of 20 high frequency three-syllable words were constructed based on frequency of use in common Portuguese spoken language (Nascimento et al., 1987). Six lists of pseudo-words were constructed based on the real words by changing the consonants and maintaining the vowels as well as the word length. The subjects were instructed to repeat words or pseudo-words and to avoid any other type of speech production. Even though there were performance differences between groups there was no significant correlation between performance and cerebral activations in either group or condition. Including the performance as a confounding covariate did not affect outcome to a great extent. In particular, the differences between the literate and illiterate group were generally independent of whether the performance covariate was included in the analysis or not (Petersson et al., 2000).

Comparing the PET data between groups indicated that there was a more prominent left-sided inferior parietal (BA 40) activation in words vs pseudo-words in the literate group. In the reverse comparison (pseudo-words vs words), the literate group displayed a significant activation in the anterior insular cortex (BA 14, and 15) bilaterally and in the right inferior frontal/frontal opercular cortices (BA 44, 45, 47, and 49), left perigenual anterior cingulate cortex (BA 24, and 32), left basal ganglia (putamen, globus pallidus and head of caudate nucleus), midline anterior thalamus/hypothalamus and midline cerebellum. In the illiterate group, significant activation was only seen in the middle frontal/frontopolar region (BA 10). In general, the interaction analysis confirmed these differences between the literate and the illiterate group. In particular, the literate group activated more strongly the right frontal opercular-anterior insular region, left anterior cingulate, left lentiform nucleus, and anterior thalamus/hypothalamus in pseudo-words vs words compared to the illiterate group (Fig. 2).

These results represented a first indication that the functional architecture of language processing may be influenced by learning to read and write, also pointing in the direction that there may exist a relation between the acquisition of alphabetic orthographic knowledge and some aspects of phonological processing. 

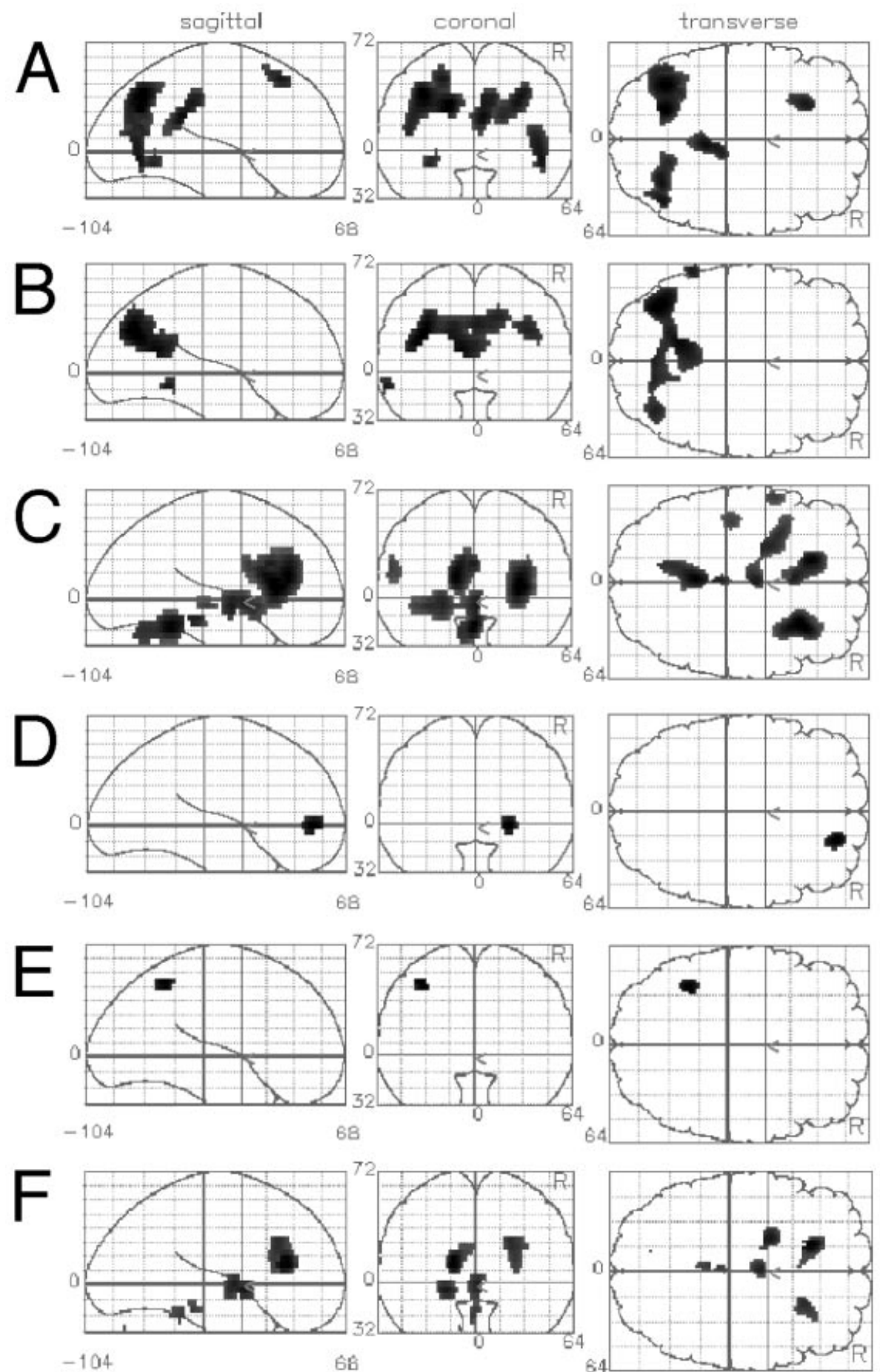

Fig. 2. Word and pseudo-word repetition in the literate and illiterate group. Maximum intensity projections for the words vs. pseudo-words in the literate (A) and in the illiterate (B) groups. The reverse contrast (pseudo-words vs. words) in the literate (C) and in the illiterate (D) groups. (E) The results from the interaction analysis [group $\times($ words - pseudo-words)] and $(\mathrm{F})$ the interaction contrast [group $\times$ (pseudowords - words)]. 


\section{IMMEDIATE VERBAL SERIAL RECOGNITION}

The relation between literacy and phonological awareness has been discussed since the pioneering work of Morais et al. (1979) demonstrating that illiterate subjects have difficulty dealing with tasks requiring explicit phonological processing. For example, they had trouble in adding or removing phonemes at the beginning of words and pseudo-words (Morais et al., 1979). However, it is still an open question which type of relation exist between phonological processing, working memory, and the acquisition of orthographic knowledge. Perhaps the acquisition of reading and writing skills modulates the system for phonological processing resulting in a language system with more fine-grained sublexical representations. Alternatively, the system for orthographic representations may support phonological processing as an auxiliary interactive network or representation.

Because several aspects of auditory-verbal language may differ between literate and illiterate subjects it is of interest to isolate the different sources contributing to these differences in phonological processing between literacy groups. In particular, it is important to study the differences in phonological processing relatively independent of lexicality effects and articulatory mechanisms. In order to do so we used an immediate auditory-verbal serial recognition paradigm (Petersson et al., in preparation). Immediate serial recognition is independent of speech output and serial recognition of pseudo-words is relatively independent of lexicality effects. In this experiment 17 illiterates (mean age $65.7 \mathrm{yrs}$ ) and 17 literates (64.7 yrs; no difference, $P=0.5$; mean number of school years 4.5) served as subjects.

From an original set of 221 words, several different lists of $\mathrm{CVCV}$ items were constructed for the serial recognition task. Lists varied in lexicality (words/pseudo-words $=\mathrm{W} / \mathrm{PW}$ ) and phonological similarity (dissimilar $/$ similar $=\mathrm{D} / \mathrm{S}$ ). For each condition we used 16 lists of 3 items. The task was recorded in a $\mathrm{CD}$ and presented by earphones. In the recognition task the subjects had to judge whether two lists presented one after the other contained items presented in the same or different sequence. The subject's answer was given by answering yes/no, respectively. The beginning of each condition was announced by a tone followed by an interval of $800 \mathrm{~ms}$ before the first item of the first list in a condition was presented (ISI $=400 \mathrm{~ms}$ ). Immediately after a given list had been presented (1200 ms interval), the same items were re-presented a second time, either in the same or in a different order. The four different conditions were randomly presented across subjects.

Group comparisons (Mann-Whitney U Test) indicated that there were significant differences between the two literacy groups (Table 6a,b) in all conditions (PW-D, $P=0.0001 ; \quad$ W-S, $\quad P=0.003 ; \quad$ PW-S, $\quad P=0.038$ ) except recognition of phonologically different words (W-D, $P=0.19)$.
Table 6a. Auditory-verbal serial recognition: mean scores and standard deviations of correctly recognized items as a function of lexicality and phonological similarity for the literate group

\begin{tabular}{lll}
\hline Literates & & Recognition \\
\hline & Phonologically Similar & $13.7 \pm 1.7$ \\
Words & Phonologically Dissimilar & $15 \pm 1$ \\
& Phonologically Similar & $12.3 \pm 1.9$ \\
Pseudo-words & Phonologically Dissimilar & $15 \pm 0.9$ \\
\hline
\end{tabular}

Table 6b. Auditory-verbal serial recognition: mean scores and standard deviations of correctly recognized items as a function of lexicality and phonological similarity for the illiterate group

\begin{tabular}{lll}
\hline Illiterates & & Recognition \\
\hline & Phonologically Similar & $11.2 \pm 2.6$ \\
Words & Phonologically Dissimilar & $14.4 \pm 1.4$ \\
& Phonologically Similar & $10.4 \pm 2.8$ \\
Pseudo-words & Phonologically Dissimilar & $12.4 \pm 2.1$ \\
\hline
\end{tabular}

A nested repeated measures mixed effects ANOVA indicated significant effects of literacy $(P<0.001)$, lexicality (i.e., word vs pseudo-word; $P<0.001$ ), and phonological similarity $(p<0.001)$, with a significant interaction between the factors $(P<0.02)$. These results are consistent with the pseudo-word repetition and digit span results showing differences in verbal working memory. In addition, they indicate that there are primary differences in phonological processing between the two literacy groups (relatively) independent of lexicality effects, articulatory organizational (e.g., output phonology) or speech output mechanisms. This allows us to suggest that there are differences in phonological processing, between literate and illiterate subjects, at the perceptual or input phonological level.

\section{A BRIEF DIGRESSION-MOTIVATIONS FOR A NETWORK APPROACH TO THE FUNCTIONAL ARCHITECTURE OF THE BRAIN}

An important aim of cognitive neurophysiological investigations of the brain is to characterize the information processing or the cognitive-behavioral relevance of neuronal dynamics. The underlying assumption is that functional neuroimaging observations express the activity of large groups of neurons, representing the firing of action potentials and the synaptic interactions of a multitude of individual neurons leading to emergent large-scale phenomena at the behavioral-cognitive level. It appears that the connection between the micro- and macroscopic levels of cerebral functions must be provided by bridging theoretical models that indicate the relevance of different observational variables. Since the details of the underlying microscopic system are not fully understood nor the level of detail 
required for the generation of the sampled or averaged phenomena, it has been suggested that between the full theory and the experiment there is a creative role for computer simulations, both experimental and theoretical (Amit, 1998). A deeper understanding of this requires a theoretical framework that connects the presumed underlying infrastructure for information processing to the largescale dynamics.

A compelling reason for a network approach to the understanding of brain function is the neuroanatomic organization of the brain itself. The organization of the brain resembles a hierarchically structured, recurrently connected network composed of different brain areas, consisting of several types of processing elements and synaptic connections, that is, classes of neurons and neuronal projections with different processing properties (Felleman \& Van Essen, 1991; Shepherd, 1997). In addition, it seems that the basic computational unit of the brain, the neuron and its interconnections via synapses (Koch, 1998; Koch \& Segev, 1998), are relatively slow and imprecise in relation to the task demands for the precision and rapid real time processing that subserves complex brain functions. One possible solution to this apparent paradox is that the brain processes information interactively in parallel and that rapid, fault tolerant, and robust processing properties emerges from such processing principles (Arbib, 1995). Several approaches to brain function have suggested that perceptual, sensorimotor and cognitive functions are the result of interactions between different brain regions or neuronal assemblies. These approaches include, for example, the perspectives of theoretical modeling (Arbib, 1995), cognitive psychology (Rumelhart \& McClelland, 1986), and cognitive neuroscience (Koch \& Davis, 1994), and brain mapping based on electrophysiological (Gevins et al., 1999) and regional hemodynamic/metabolic methods (Horwitz et al., 1999; McIntosh \& Gonzalez-Lima, 1994). Information is thought to be represented as distributed activity in the brain and information processing, subserving complex cerebral functions, are hypothesized to emerge from the interactions between different functionally specialized regions or neuronal groups. A network approach is therefore natural when trying to describe the workings of the brain; analyzing the dynamic patterns of interaction between different functionally specialized brain regions or neuronal assemblies should contribute to the understanding of sensorimotor and cognitive functions. Furthermore, learning and memory are fundamental brain functions enabling the central nervous system to encode experiential information and adapt in a non-stationary environment. Learning may be defined as the processes by which the brain functionally restructures its processing networks or its representations of information, as a function of experience. The stored information or the memory trace can then be viewed as the resulting changes in the processing system. From this perspective, learning in a neural network is the dynamic consequence of information processing and network plasticity, the fundamental principle being the colocalization of memory and processing at a microscopic level. For a more elaborated discussion of these issues see (Ingvar \& Petersson, 1999).

One principle that has emerged in neuroscience is that of functional specialization or functional segregation (Frackowiak et al., 1997; Zeki, 1978). The idea of functional specialization rests on the hypothesis that different brain regions are specialized and implement different computations or operations on representations of information. This principle is reflected in one of the general approaches to the analysis of functional neuroimaging data, the activation approach, also known as the subtraction approach (Fox et al., 1988). The activation approach is commonly based on the general linear model (Frackowiak et al., 1997). This approach commonly aims at identifying regions that respond selectively to specific aspects of sensorimotor or cognitive processing by referring data from an activation state to an appropriately defined reference state. Under the assumption that the activation and reference states differ in some relevant specific aspect of sensorimotor or cognitive processing, the locations of statistically significant differences in signal between the states presumably define brain regions that are related to this difference. Specifically, it is assumed that these regions are differentially involved in the two conditions reflecting the differences in processing of the two conditions. For example, if the two conditions differed by the presence of an additional cognitive operation in one compared to the other, then the brain areas activated would, it is assumed, reflect the cognitive operation in question. Since this approach subtracts data obtained during two or more experimental conditions to decompose a task of interest, this approach is crucially dependent on an adequate choice of states to compare. The formulation of the reference condition is an important and difficult issue in functional neuroimaging. A complication in the interpretation of results from functional neuroimaging studies based on the subtraction of functional images is whether a given brain function is well approximated as a linear additive decomposition into sub-components, or, rather under which circumstances or comparisons they may be.

Since functional specialization refers to specific aspects or sub-components of sensorimotor and cognitive processing, this principle presupposes another principle of neuroscience, the principle of functional integration. This principle is reflected in another general approach to the analysis of functional neuroimaging data, which in its simplest form is represented by the covariance approach and in a more elaborate form as a network approach (Horwitz et al., 1992). The covariance approach studies the covariance structure observed in functional neuroimaging data based on the idea that brain regions that constitute components of a functional network will have activities that are correlated. In contrast, the subtraction approach 
and its generalizations are used to analyze the relative changes in regional activity and how these changes covary with specific external experimental manipulations, changes over which experimental control is exerted. In this way the activation approach can be used to identify components or brain regions of large-scale functional networks. As already indicated, the understanding of different brain functions can benefit from analyzing the interactions between brain regions, that is, a network approach to the analysis of functional neuroimaging data. The basic hypothesis of the network approach as applied to functional neuroimaging data is that the intrinsic variability in the neural response of a cognitive state will depend on the relevant functional interactions and that these interactions will be reflected in the covariance structure observed. For a more elaborated discussion of these issues and limitations related to the subtraction and network approaches see (Ingvar \& Petersson, 1999; Petersson et al., 1999a; Petersson et al., 1999b).

\section{STRUCTURAL EQUATION MODELING IN FUNCTIONAL NEUROIMAGING}

To characterize effective connectivity in functional neuroimaging data a network approach based on structural equation modeling (Bollen, 1989) was suggested by McIntosh and Gonzalez-Lima (1994). Structural equation modeling SEM provides the opportunity to investigate functional-anatomical models emulating different brain functions in terms of which regions are involved and how they interact in a given network model. In order to characterize a large-scale functional network, a specific functional-anatomical model is used in conjunction with SEM to model the observed covariance structure between the regions included in the model. The functionalanatomical model is specified by selecting the network components (i.e., brain regions represented by regions of interest or voxels) and the connections between the components based on theoretical or empirical considerations. The covariances between the network components are computed and finally the connection strengths (also called path coefficients or connection weights) are estimated. Differences between conditions or groups can then be tested using a stacked models approach (Bollen, 1989; McIntosh \& Gonzalez-Lima, 1994).

Finally, it should also be noted that several related approaches to functional or effective connectivity (Frackowiak et al., 1997) have been proposed. For example, McIntosh and Gonzalez-Lima (1994) describe a simple model for studying the effects of experimental manipulation on both regional activity and interregional covariance. This approach has since become known as psychophysiological interactions (Friston et al., 1997). Furthermore, it has been suggested that exploration of the interface between functional neuroimaging, network analysis and large-scale neural modeling may be productive and increase our understanding of human cognition (Amit, 1998; Friston, 1998; Horwitz, 1998).

\section{A NETWORK ANALYSIS OF IMMEDIATE VERBAL REPETITION IN LITERATE AND ILLITERATE SUBJECTS}

There are several general reasons for a network approach to the understanding of brain function including the neuroanatomic organization of the brain itself. Generally, information is thought to be represented as distributed activity in the brain and information processing, subserving complex cerebral functions, is hypothesized to emerge from the interactions between different functionally specialized regions or neuronal groups. A network approach is therefore natural when trying to understand the functionality of the brain, in particular, when analyzing dynamic patterns of interaction between different functionally specialized brain regions (Ingvar \& Petersson, 1999).

We have previously suggested that the parallel interactive processing characteristics of the underlying language-processing system of the brain differ in literate and illiterate subjects (Petersson et al., 2000). Structural equation modeling (SEM) provides an opportunity to explicitly test hypotheses relating to functional-anatomical models subserving different cognitive functions in terms of which regions are involved and how they interact in a given network model. The network approach characterizes the functional organization in terms of effective connections between regions in a specific functional-anatomical model.

\section{A SIMPLE FUNCTIONAL-ANATOMICAL NETWORK MODEL FOR VERBAL REPETITION}

Generally the functional-anatomical model is specified by selecting the network components and the connections between the components based on theoretical or empirical considerations. The objective when constructing our functional-anatomical model for language processing during verbal repetition was to generate a simple network that could explain a sufficient part of the observed covariance, both in the literate and illiterate group, during word as well as pseudo-word repetition. Data were generated from a previously reported data-set (Castro-Caldas et al., 1998). At the same time we required that the network model should be both theoretically and empirically plausible based on the literature on the functional organization of language and the activations observed with the activation approach in the particular data-set (Castro-Caldas et al., 1998; Petersson et al., 2000).

The functional-anatomical network model used included several regions of interest (ROIs) (Table 7, Fig. 3) and interconnections (Fig. 4). 
For simplicity we decided to restrict our analysis to a left hemisphere language network. The right hemisphere language representation is less well known compared to the left hemisphere organization of language, in particular in illiterate subjects. There are some indications that language processing in illiterate subjects may under certain circumstances recruit bilateral brain regions to a greater extent than literate subjects (Petersson et al., 1998; Petersson et al., 1999c). In addition, some brain lesion data have been

Table 7. The spherical regions of interest used in the functionalanatomical network model, located with the help of the Karolinska Computerized Brain Atlas of Greitz (Greitz et al., 1991)

\begin{tabular}{lll}
\hline Region of interest & Brodmann area & \\
\hline Primary auditory cortex, left & BA 41/42 & S \\
Wernicke's area, left & BA 22 & W \\
Angular/supramarginal gyrus, left & BA 39/40 & IPC \\
Posterior-mid insula, left & BA 13 & INS \\
Broca's area, left & BA 44 & B \\
Lentiform nucleus, left & & NcL \\
Lateral cerebellum, right & & Cdx \\
Primary motor region (mouth area), left & BA 4 & M \\
Anterior cingulate cortex, left & BA 24/32 & ACC \\
Prefrontal cortex, left & BA 45/46 & PFC \\
\hline
\end{tabular}

interpreted as indicating that the functional architecture of language is more bilaterally organized in illiterate compared to literate subject (Cameron et al., 1971; Lecours et al., 1987a; Lecours et al., 1987b; Wechsler, 1976). However, this issue is complex and there are other data indicating that this may not always be the case (Damásio et al., 1976a; Damásio et al., 1976b). Furthermore, it is unclear how the right and left hemispheric language networks interact. However, given the possibility of a greater bilateral language processing in the illiterate compared to literate subjects, it is not inconceivable that the inclusion of a right hemispheric network would accentuate the differences between the two literacy groups. For more details on the construction of the functional-anatomical network model see Petersson et al. (2000).

In summary, the network model (Fig. 4) includes a simplification of the Wernicke-Geschwind model represented by the Wernicke's area (W) connected to Broca's area (B) with input from the left primary/secondary auditory cortex (S) and a simple motor output circuit (left lenticular nucleus, NcL; left primary motor cortex for articulation). This core was extended to include the anterior cingulate cortex (ACC) hypothesized to be related to focused attention, error detection and response competition/selection. Furthermore, the network model was ex-

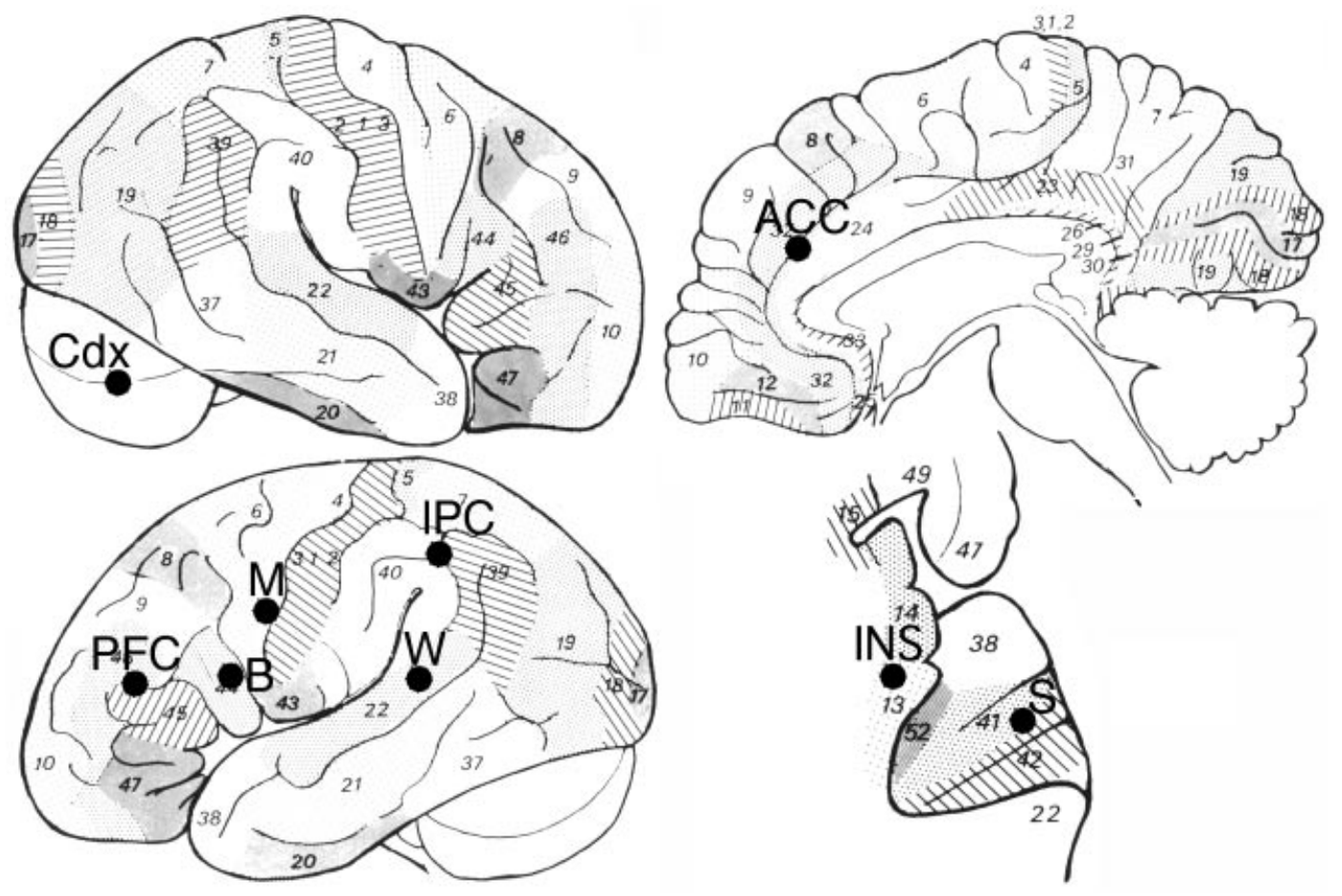

Fig. 3. The anatomical localization of the regions of interest displayed in the anatomical space of Greitz (Greitz et al., 1991). The numbers displayed on the atlas correspond to the Brodmann areas. $\mathrm{S}=$ primary/secondary auditory cortex, $\mathrm{W}=\mathrm{Wernicke}$ 's area, IPC $=$ inferior parietal (angular/supramarginal gyrus) cortex, $\mathrm{INS}=$ posterior-mid insula, $\mathrm{B}=$ Broca's area, $\mathrm{M}=$ primary motor region of the mouth and larynx, $\mathrm{Cdx}=$ right lateral cerebellum, $\mathrm{ACC}=$ anterior cingulate cortex, and $\mathrm{PFC}=$ middle-inferior prefrontal cortex. The location of the lentiform nucleus is not shown. 
tended to include the phonological loop as described by (Paulesu et al., 1993; Paulesu et al., 1996), introducing the inferior parietal cortex (IPC, BA 39/40) and the posteriormid insula (INS). The connections of the phonological loop were generally recurrent. Since the insula has been hypothesized to be a neural relay for automatic language processing the connections to and from the posterior-mid insula were feedforward (Raichle et al., 1994). In addition, the left middle-inferior dorsolateral prefrontal region (PFC, BA 45/46) suggested to subserve central executive aspects of verbal working memory, and finally, the right lateral cerebellar region $(\mathrm{Cdx})$ was included since this region has been related to certain aspects of language processing. For a general review of functional neuroimaging studies of cognition, including language processing, see (Cabeza \& Nyberg, 1997; Cabeza \& Nyberg, 2000).

Derived values of cerebral activity within group and state in the regions of interest were entered into the model, the observed pattern of covariances within state and group were decomposed according the network model developed, and finally estimates of the path coefficients or connection strengths were generated. Following that comparisons of the patterns of network interactions, as indicated by the connection strengths, were made between groups and states.

We used a hierarchical approach to test for differences between states and groups (Table 8). In a first step we tested whether the same model using a stacked analysis could explain the network interactions in both conditions and groups. This was not the case $(P=0.003)$. We then tested for differences either between groups in a given state or between states in a given group. Finally, in a second step we characterized the differences between word and pseudo-

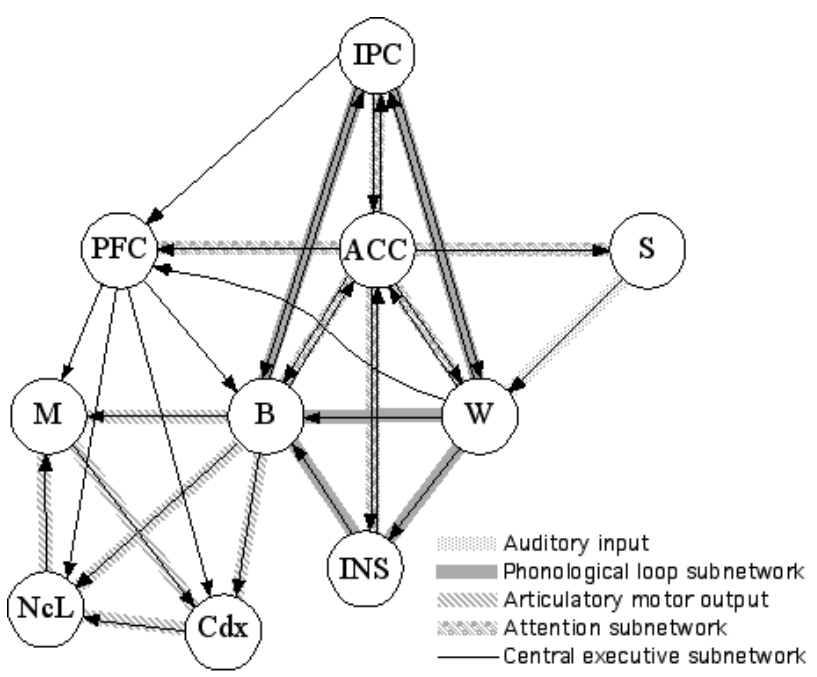

Fig. 4. The connectivity of the functional-anatomical network model for language processing with the sub-networks outlined; the auditory input, the phonological loop, the articulatory motor subnetwork, the attention sub-network, and the central executive subnetwork.
Table 8. The results from the omnibus stacked model comparisons between the different literacy groups and tasks, ns.=non-significant

\begin{tabular}{ll}
\hline Omnibus comparison & P-value \\
\hline $\begin{array}{ll}\text { Literate group, word/pseudo-word repetition, illiterate, } \\
\text { word/pseudo-word repetition }\end{array}$ & 0.003 \\
$\begin{array}{ll}\text { Literate group, word vs. pseudo-word repetition } \\
\text { Illiterate group, word vs. pseudo-word repetition }\end{array}$ & ns. \\
Word repetition, literate vs. illiterate group & 0.002 \\
Pseudo-word repetition, literate vs. illiterate group & 0.038 \\
\hline
\end{tabular}

word repetition in the illiterate group as well as the differences between the literate and the illiterate group repeating pseudo-words. Specifically, we localized the observed differences, as far as the sensitivity in this study allowed to, within the different sub-networks and only the connections showing relative differences $\geq 0.15$ (standardized units) in connection strength were further investigated.

There was no significant difference in the pattern of network interactions between word and pseudo-word repetition in the literate group. Neither was there any significant difference between the literate and illiterate group repeating words. In contrast, there were significant differences in the network interactions between word and pseudoword repetition in the illiterate group, and in line with this, there were significant differences between the literate and illiterate group in repeating pseudo-words. We characterized the differences between word and pseudo-word repetition in the illiterate group (Table 9, Fig. 5) as well as the literate and the illiterate group repeating pseudo-words (Table 9, Fig. 6).

The results of this study indicate that the network interactions were relatively similar during word and pseudo-word repetition in literate subjects and also when literate and illiterate subjects repeated words. In contrast, there were significant differences in the network interactions

Table 9. The results from the sub-network stacked word vs. pseudoword repetition comparisons in the illiterate group and the subnetwork stacked literate vs. illiterate group during pseudo-word repetition. For more detailed results see the Results section. Only connections showing differences $=0.15$ in standardized units were investigated, $n s,=$ non-significant

Omnibus subnetwork comparison P-value

Illiterate group, word vs. pseudo-word repetition

Attention subnetwork

P-value

Central executive subnetwork

0.024

Phonological loop

Articulatory motor output

0.047

ns.

0.052

Pseudo-word repetition, literate vs. illiterate group

Attention subnetwork

0.034

Central executive subnetwork

0.045

Phonological loop

0.036

Articulatory motor output 


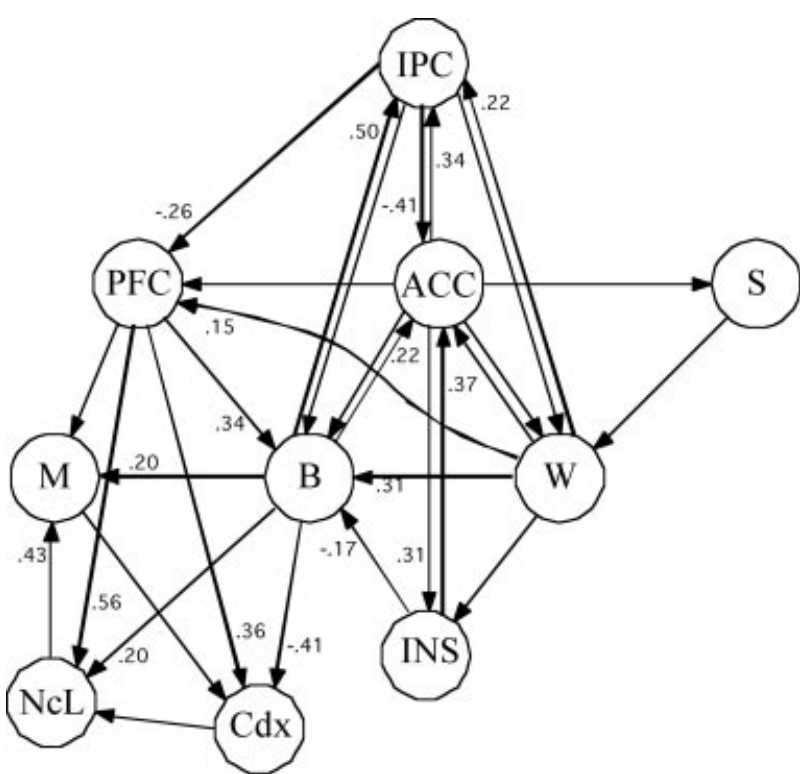

Fig. 5. The relative differences between word and pseudo-word repetition in the illiterate group, that is, the difference between the corresponding connection strengths (word-pseudo-word). Only differences $\leq 0.15$ in standardized units are shown. The omnibus comparison indicated that the difference were significant $(\mathrm{P}=0.002)$.

when the illiterate subjects repeated words compared to pseudo-words. These differences were mainly related to those parts of the language network that may be viewed as general support and control systems, that is, central executive aspects of processing as well as attentional modulation. In addition, there were differences related to the motor circuit hypothesized to support the organization of articulatory output.

The results also indicated significant differences between the literate and illiterate subjects when repeating pseudowords. These differences were related to the phonological loop, in particular the interactions between Broca's area and the inferior parietal region. There were also differences related to the posterior-mid insular bridge between Wernicke's and Broca's area. Additional differences related to attentional modulation of the auditory input, the Broca's and the posterior-mid insular regions as well as executive aspects of language processing and articulatory output.

The absence of significant difference between word and pseudo-word repetition in the literate group indicates that the network interactions are relatively similar in word and pseudo-word repetition. In other words, it appears that the literate subjects automatically recruit a phonological processing network for sub-lexical processing during simple immediate verbal repetition (words or pseudo-words), while this is not the case for the illiterate group, as this part of the language system hypothetically is differently developed in the illiterate subjects. Accordingly, the network interactions differed significantly between word and pseudo-word

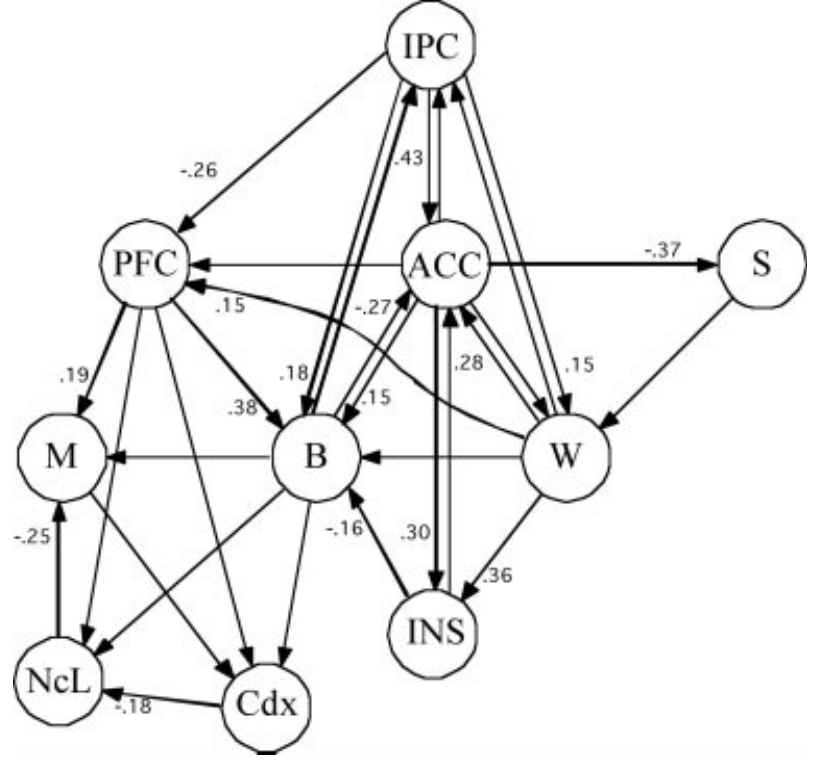

Fig. 6. The relative differences during pseudo-word repetition between the literate and the illiterate group, that is, the difference between the corresponding connection strengths (literate - illiterate). Only differences $\geq 0.15$ in standardized units are shown. The omnibus comparison indicated that the difference were significant at $(\mathrm{P}=0.038)$.

repetition in the illiterate group, indicating that the illiterate subjects process words and pseudo-words differently during verbal repetition. In line with this, the network interactions were significantly different when the literate and illiterate group repeated pseudo-words, lending support to the interpretation that the illiterate group process pseudo-words in a qualitatively different fashion as compared to literate subjects. Based on the immediate auditory-verbal serial recognition results previously described, we suggest that the differences in the phonological loop interactions, perhaps in conjunction with the differences in the interaction between the phonological loop and the attentional sub-network, represent the primary difference between the two groups. The differences related to the executive aspects of verbal working memory and the articulatory organization of speech output may then be interpreted as reflecting compensatory and secondary effects, respectively.

\section{CONCLUSION}

The study of illiterate subjects, which for specific sociocultural reasons did not have the opportunity to acquire basic reading and writing skills, represents one approach to the study the interactions between neurobiological and cultural factors in cognitive development and the functional organization of the human brain. Recently, using a different approach, an confirming the cultural influence on the brain, it was indicated that aspects of language function may be differently organized in different languages (Paulesu et al., 
2000). In addition the naturally occurring illiteracy may serve as a model for studying the influence of alphabetic orthography on auditory-verbal language. Furthermore, it has been suggested that literacy and formal schooling have consequences not only on our linguistic but also on our nonlinguistic information processing capacities (Morais \& Kolinsky, 2000). In this paper we have reviewed some recent behavioral and functional neuroimaging data indicating that learning an alphabetic written language modulates the auditory-verbal language system in a non-trivial way and provided support for the hypothesis that the functional architecture of the brain is modulated by literacy. We have also indicated that the effects of literacy and formal schooling is not limited to language related skills but appears to affect also other cognitive domains. In particular, we indicate that formal schooling influences $2 \mathrm{D}$ but not 3D visual naming skills. We have also pointed to the importance of using ecologically relevant tasks when comparing literate and illiterate subjects. Thus it appears that formal schooling has a significant influence on the development of the human brain.

We have also demonstrated the applicability of a network analysis approach in elucidating differences in the functional organization of the brain between groups. The strength of such an approach is the ability to study patterns of interactions between functionally specialized brain regions and the possibility to compare such patterns of brain interactions between groups or functional states. This complements the more commonly used activation approach to functional neuroimaging data, which characterize functionally specialized regions, and provides important data characterizing the functional interactions between these regions.

This study is part of the EU grant (QLK6-CT-99-02140) and was financed in part by grants from the Swedish Medical Research Council $(8276,12716)$, the Knut and Alice Wallenberg Foundation, and the Swedish Dyslexia Association. The authors also want to thank the volunteers for their participation, Dr Fransisco Reis who assisted in the recruitment of subjects and the help of the Portuguese Embassy in Stockholm, Professor Alexandre Castro-Caldas for introducing us to the subject matter, Dr Fransisco Lacerda and psychologist Catarina Silva for their assistance in the immediate serial recognition experiment.

\section{REFERENCES}

Amit, D. J. (1998). Simulation in neurobiology: Theory or experiment? Trends in Neuroscience, 21, 231-237.

Arbib, M. A. (1995). The handbook of brain theory and neural networks, MIT Press, Cambridge, MA.

Ardila, A., Rosselli, M. \& Rosas, P. (1989). Neuropsychological assessment in illiterates: Visuospatial and memory abilities. Brain and Cognition, 11, 147-166.

Baddeley, A. (1992). Working memory. Science, 255, 556-559.

Baddeley, A., Gathercole, S. \& Papagno, C. (1998). The phonological loop as a language learning device. Psychological Review, $105,158-173$.
Baddeley, A. D. \& Hitch, G. J. (1974). Working memory. In G. H. Bower (Ed.), The Psychology of Learning and Motivation (pp. 47-89). Academic Press, New York.

Bollen, K. A. (1989). Structural equations with latent variables. Wiley, New York.

Brady, S. A. (1991). The role of working memory in reading disability. In S. A. Brady and D. P. Shankweiler (Eds.), Phonological Processes in Literacy (pp. 129-151). Lawrence Erlbaum Associates, Hillsdale, New Jersey.

Brooks, D. N. \& Truelle, J.-L. (1994). Head Injury Evaluation Chart. EBIS Document, European Brain Injury Society.

Cabeza, R. \& Nyberg, L. (1997). Imaging cognition: An empirical review of PET studies with normal subjects. Journal of Cognitive Neuroscience, 9, 1-26.

Cabeza, R. \& Nyberg, L. (2000). Imaging Cognition II: An Empirical Review of 275 PET and fMRI Studies. Journal of Cognitive Neuroscience, 12, 1-47.

Cameron, R. F., Currier, R. D. \& Haerer, A. F. (1971). Aphasia and literacy. British Journal of Disorders of Communication, 6, 161163.

Castro-Caldas, A., Miranda Cavaleiro, P., Carmo, I., Reis, A., Leote, F., Ribeiro, C. \& Ducla-Soares, E. (1999). Influence of learning to read and write on the morphology of the corpus callosum. European Journal of Neurology, 6, 23-28.

Castro-Caldas, A., Petersson, K. M., Reis, A., Stone-Elander, S. \& Ingvar, M. (1998). The illiterate brain: Learning to read and write during childhood influences the functional organization of the adult brain. Brain, 121, 1053-1063.

Damásio, A. R., Castro-Caldas, A., Grosso, J. T. \& Ferro, J. M. (1976a). Brain specialization for language does not depend on literacy. Archives of Neurology, 33, 300-301.

Damásio, A. R., Castro-Caldas, A., Grosso, J. T. \& Ferro, J. M. (1976b). Letter to the Editor. Archives of Neurology, 33, 662.

Felleman, D. J. \& Van Essen, D. C. (1991). Distributed hierarchical processing in the primate cerebral cortex. [Review]. Cerebral Cortex, 1, 1-47.

Fox, P. T., Mintun, M. A., Reiman, E. M. \& Raichle, M. E. (1988). Enhanced detection of focal brain responses using intersubject averaging and change-distribution analysis of subtracted PET images. Journal of Cerebral Blood Flow and Metabolism, 8, $642-653$.

Frackowiak, R., Friston, K., Frith, C., Dolan, R. \& Mazziotta, J. (1997). Human Brain Function, Academic Press, San Diego, CA.

Friston, K. J. (1998). Imaging neuroscience: Principles or maps? Proceedings of the National Academy of Sciences, USA, 95, 796-802.

Friston, K. J., Buechel, C., Fink, G. R., Morris, J., Rolls, E. \& Dolan, R. J. (1997). Psychophysiological and modulatory interactions in neuroimaging. NeuroImage, 6, 218-229.

Garcia, C. (1984). A Doença de Alzheimer: Problemas de Diagnóstico Clínico. University of Lisbon, Lisbon.

Garcia, G. \& Guerreiro, M. (1983). Pseudo-dementia in illiteracy. 6th European meeting of the International Neuropsychological Society, Lisbon 14-17 June.

Gathercole, S. E. (1995a). The assessment of phonological memory skills in preschool children. British Journal of Education and Psychology, 65, 155-164.

Gathercole, S. E. (1995b). Is nonword repetition a test of phonological memory or long-term knowledge? It all depends on the nonwords. Memory \& Cognition, 23, 83-94.

Gathercole, S. E. (1995c). Nonword repetition: More than just a phonological output task. Cognitive Neuropsychology, 12, 857-861.

Gathercole, S. E. \& Baddeley, A. D. (1995). Working Memory and Language, Lawrence Erlbaum Associates, Hillsdale, New Jersey. 
Gevins, A., Smith, M. E., McEvoy, L. K., Leong, H. \& Le, J. (1999). Electroencephalographic imaging of higher brain function. Philosophical Transactions of the Royal Society London, B 354, $1125-1134$.

Goldblum, M.-C. \& Matute de Duran, E. (2000). Are illiterate people deep dyslexic? Journal of Neurolinguistics, 2, 103-111.

Greitz, T., Bohm, C., Holte, S. \& Eriksson, L. (1991). A computerized brain atlas: construction, anatomical content and some applications. Journal of Computer Assisted Tomography, $15,26-38$.

Horwitz, B. (1998). Using functional brain imaging to understand human cognition. Complexity, 3, 39-52.

Horwitz, B., Soncrant, J. V. \& Haxby, J. V. (1992). Covariance analysis of functional interactions in the brain using metabolic and blood flow data. In F. Gonzalez-Lima, T. Finkenstaedt and H. Scheich (Eds.), Advances in Metabolic Mapping Techniques for Brain Imaging of Behavioral and Learning Functions (pp. 189-217). Kluwer Academic Publishing, Dordrecht, The Netherlands.

Horwitz, B., Tagamets, M.-A. \& McIntosh, A. R. (1999). Neural modeling, functional brain imaging, and cognition. Trends in Cognitive Sciences, 3, 91-98.

Ingvar, M. \& Petersson, K. M. (1999). Functional maps and brain networks. In A. W. Toga and J. C. Mazziotta (Eds.), Brain Mapping: The Systems (pp. 111-140). Academic Press, San Diego, CA.

Koch, C. (1998). Biophysics of Computation: Information Processing in Single Neurons, ed. Oxford University Press, New York.

Koch, C. \& Davis, J. L. (1994). Large-Scale Neuronal Theories of the Brain, ed. MIT Press, Cambridge, MA.

Koch, C. \& Segev, I. (1998). Methods in Neuronal Modeling: From Ions to Networks, 2nd ed. MIT Press, Cambridge, MA.

Kremin, H., Deloche, G. \& Metz-Lutz, M.-N. (1991). The effect of age, educational background and sex on confrontation naming in normals; principles for testing naming ability. Aphasiology, 5, $579-582$.

Lecours, A. R., Mehler, J., Parente, M. A., Aguiar, L. R., Silva, A. B., Caetano, M., Camarotti, H., Castro, M. J., Dehaut, F., Dumais, C., Gauthier, L., Gurd, J., Leitão, O., Maciel, J., Machado, S., Melaragno, R., Oliveira, L. M., Paciornik, J., Sanvito, W., Silva, E. S., Silifrandi, M. \& Torné, C. H. (1987a). Illiteracy and Brain Damage: 2. Manifestations of unilateral neglect in testing "auditory comprehension" with iconographic materials. Brain and Cognition, 6, 243-265.

Lecours, A. R., Mehler, J., Parente, M. A., Beltrami, M. C., Silva, A. B., Tolipan, L. C., Cary, L., Castro, M. J., Carrono, V., Chagastelles, L., Dehaut, F., Delgado, R., Evangelista, A., Fajgenbaum, S., Fontoura, C., Karmann, D. F., Gurd, J., Torné, C. H., Jakubovicz, R., Kac, R., Lefevre, B., Lima, B., Maciel, J., Mansur, L., Martinez, R., Nobrega, M. C., Osorio, Z., Paciornik, J., Papaterra, F., Penedo, M. A. J., Saboya, B., Scheuer, C., Silva, A. B., Spinardi, M. \& Teixeira, M. (1987b). Illiteracy and Brain Damage: 3. A contribution to the study of speech and language disorders in illiterates with unilateral brain damage. Neuropsychologia, 26, 575-589.

Manly, J. J., Jacobs, D. M., Sano, M., Bell, K., Merchant, C. A. \& Small, S. A. (1999). Effect of literacy on neuropsychological test performance in nondemented, education-matched elders. Journal of the International. Neuropsychological Society, 5, 191-202.

McIntosh, A. R. \& Gonzalez-Lima, F. (1994). Structural equation modeling and its application to network analysis in functional brain imaging. Human Brain Mapping, 2, 2-22.

Morais, J., Cary, L., Alegria, J. \& Bertelson, P. (1979). Does awareness of speech as a sequence of phones arise spontaneously? Cognition, 7, 323-331.
Morais, J. \& Kolinsky, R. (2000). Biology and culture in the literate mind. Brain and Cognition, 42, 47-49.

Nascimento, M. F. B., Rivenc, P. \& Cruz, M. L. S. (1987). Portugues fundamental, metodos e documentos. Instituto Nacional de Investigacao Cientifica, Centro de Linguistica da Universidade de Lisboa.

Newcombe, F., Oldfield, R. C., Ratcliff, G. G. \& Wingfield, A. (1971). Recognition and naming of object-drawings by men with focal brain wounds. Journal of Neurology Neurosurgery and Psychiatry, 34, 329-340.

Ostrosky, F., Efron, R. \& Yund, E. W. (1991). Visual detectability gradients: Effect of illiteracy. Brain and Cognition, 17, 42-51.

Ostrosky-Solís, F., Ardila, A. \& Rosselli, M. (1999). NEUROPSI: A brief neuropsychological test battery in Spanish with norms by age and educational level. Journal of the International Neuropsychological Society, 5, 413-433.

Ostrosky-Solís, F., Ardila, A., Rosselli, M., Lopez-Arango, G. \& Uriel-Mendonza, V. (1998). Neuropsychological test performance in illiterate subjects. Archives of Clinical Neuropsychology, $13,645-660$.

Patterson, K. \& Lambon Ralph, M. A. (1999). Selective disorders of reading? Current Opinion in Neurobiology, 9, 235-239.

Paulesu, E., Frith, C. D. \& Frackowiak, R. S. J. (1993). The neural correlates of the verbal component of working memory. Nature, $362,342-344$

Paulesu, E., Frith, U., Snowling, M., Gallagher, A., Morton, J., Frackowiak, R. S. J. \& Frith, C. D. (1996). Is developmental dyslexia a disconnection syndrome? Evidence from PET scanning. Brain, 119, 143-157.

Paulesu, E., McCrory, E., Fazio, F., Menoncello, L., Brunswick, N., Cappa, S. F., Cotelli, M., Cossu, G., Corte, F., Lorusso, M., Pesenti, S., Gallagher, A., Perani, D., Price, C., Frith, C. D. \& Frith, U. (2000). A cultural effect on brain function. Nature Neuroscience, 3, 91-96.

Petersson, K. M., Nichols, T. E., Poline, J.-B. \& Holmes, A. P. (1999a). Statistical limitations in functional neuroimaging I: Non-inferential methods and statistical models. Philosophical Transactions of the Royal Society London, B 354, 1239-1260.

Petersson, K. M., Nichols, T. E., Poline, J.-B. \& Holmes, A. P. (1999b). Statistical limitations in functional neuroimaging II: Signal detection and statistical inference. Philosophical Transactions of the Royal Society London, B 354, 1261-1282.

Petersson, K. M., Reis, A., Askelöf, S., Castro-Caldas, A. \& Ingvar, M. (1998). Differences in inter-hemispheric interactions between literate and illiterate subjects during verbal repetition. NeuroImage, 7, S217.

Petersson, K. M., Reis, A., Askelöf, S., Castro-Caldas, A. \& Ingvar, M. (2000). Language processing modulated by literacy: A network-analysis of verbal repetition in literate and illiterate subjects. Journal of Cognitive Neuroscience, 12, 364-382.

Petersson, K. M., Reis, A., Castro-Caldas, A. \& Ingvar, M. (1999c). Effective auditory-verbal encoding activates the left prefrontal and the medial temporal lobes: A generalization to illiterate subjects. NeuroImage, 10, 45-54.

Raichle, M. E., Fiez, J. A., Videen, T. O., MacLeod, A.-M. K., Pardo, J. V., Fox, P. T. \& Petersen, S. E. (1994). Practice-related changes in human brain functional anatomy during nonmotor learning. Cerebral Cortex, 4, 8-26.

Reis, A. \& Castro-Caldas, A. (1997). Illiteracy: A bias for cognitive development. Journal of the International Neuropsychological Society, 3, 444-450.

Reis, A., Guerreiro, M. \& Castro-Caldas, A. (1994). Influence of educational level of non brain-damaged subjects on visual naming capacities. Journal of Clinical and Experimental Neuropsychology, 16, 939-942. 
Reis, A., Guerreiro, M., Garcia, C. \& Castro-Caldas, A. (1995). How does an illiterate subject process the lexical component of arithmetics? Journal of the International Neuropsychological Society, 1, 206.

Reis, A., Guerreiro, M. \& Petersson, K. M. Submitted-a. A sociodemographic and neuropsychological characterization of an illiterate population.

Reis, A., Petersson, K. M., Castro-Caldas, A. \& Ingvar, M. (1999a). Illiteracy influences 2D but not 3D visual object naming. International Journal of Psychology, 35, 211.

Reis, A., Petersson, K. M., Castro-Caldas, A. \& Ingvar, M. (1999b). The modulatory influence of formal schooling on visual naming skills. European Journal of Neurology, 6 (suppl 3), 119.

Reis, A., Petersson, K. M., Castro-Caldas, A. \& Ingvar, M.
Submitted-b. Formal schooling influences two- but not threedimensional naming skills.

Rosselli, M., Ardila, A. \& Rosas, P. (1990). Neuropsychological assessment in illiterates: II. Language and praxic abilities. Brain and Cognition, 12, 281-296.

Rumelhart, D. \& McClelland, J. L. (1986). Parallel distributed processing: Explorations in the microstructures of cognition, MIT Press, Cambridge, MA.

Shepherd, G. M. (1997). The Synaptic Organization of the Brain, 4 ed. Oxford University Press, New York.

Wechsler, A. F. (1976). Crossed Aphasia in an illiterate dextral. Brain and Language, 3, 164-172.

Zeki, S. (1978). Functional specialization in the visual cortex of the Rhesus monkey. Nature, 274, 423-428. 